\title{
A Gold Standard Protocol for Human Megakaryocyte Culture Based on the Analysis of 1,500 Umbilical Cord Blood Samples
}

\author{
Christian A. Di Buduo ${ }^{1,2}$ Paolo M. Soprano ${ }^{1,2}$ Carolina P. Miguel ${ }^{1,2}$ Cesare Perotti ${ }^{3}$ \\ Claudia Del Fante ${ }^{3}$ Alessandra Balduini ${ }^{1,2,4}$
}

\author{
${ }^{1}$ Department of Molecular Medicine, University of Pavia, Pavia, Italy \\ ${ }^{2}$ Laboratory of Biochemistry, Biotechnology and Advanced Diagnosis, \\ Istituto di Ricovero e Cura a Carattere Scientifico (I.R.C.C.S.) \\ Policlinico San Matteo Foundation, Pavia, Italy \\ ${ }^{3}$ Immunohematology and Transfusion Service and Cell Therapy Unit, \\ Istituto di Ricovero e Cura a Carattere Scientifico (I.R.C.C.S.) \\ Policlinico San Matteo Foundation, Pavia, Italy \\ ${ }^{4}$ Department of Biomedical Engineering, Tufts University, Medford, \\ Massachusetts, United States
}

Thromb Haemost 2021;121:538-542.

\section{Introduction}

Three decades after the ground breaking proposal of using human umbilical cord blood (UCB) as a source of transplantable hematopoietic stem cells (HSCs), ${ }^{1}$ over 40,000 transplants have been performed worldwide. ${ }^{2}$ The hematopoietic reconstitution capacity of UCB resides in the high concentration of $\mathrm{CD} 34^{+}$cells, enriched for hematopoietic stem and progenitors cells. $^{3,4}$

Since 1993, public UCB banks have been established worldwide. In Italy, UCB is stored, free of charge, when (1) it is altruistically donated for HSC transplantation and (2) it is for a family affected with, or at risk of, a disease that is treatable with transplantation. ${ }^{5}$

UCBs that do not meet the requirements for banking based on the international standards became invaluable sources for stem cell research. ${ }^{6}$ The study of human hematopoiesis is one of the major applications as this human model can overcome drawbacks related (1) to the use of animals, which can be poor predictors of human physiology, ${ }^{7}(2)$ to the high cost and expertise necessary for generating the embryonic and induced pluripotent cell lines, ${ }^{8-10}$ or (3) to the limited supply of adult HSCs, which usually become available when discarded after clinical procedures. ${ }^{11,12}$

Different protocols have been established for in vitro megakaryocyte $(\mathrm{Mk})$ differentiation from $\mathrm{CD} 34^{+}$cells. All entail the usage of various concentrations of recombinant human thrombopoietin (TPO) in combination with a variety

Address for correspondence Alessandra Balduini, MD, Department of Molecular Medicine, University of Pavia, Via Forlanini 6, 27100 Pavia, Italy (e-mail: alessandra.balduini@unipv.it).

of hematopoietic cytokines but with contrasting results in terms of Mk and proplatelet phenotypes. ${ }^{13-16}$

We report a retrospective analysis of our 15-year experience in UCB processing, with a focus on UCB features and experimental procedures that are basic for a reproducible culture of functional Mks without the need for serum supplementation or coculture with feeder cells.

\section{Results and Discussion}

The UCB bank of the I.R.C.C.S. Policlinico San Matteo Foundation of Pavia, in Italy, collects 4 UCB units/day. After donor screening and testing for infectious agents, samples that meet the international standards for banking (currently $>1.6 \times 10^{9}$ total nucleated cells [TNCs] or $>1.2 \times 10^{9}$ TNCs and $2 \times 10^{6} \mathrm{CD} 34^{+}$cells) are stored, while the others are forwarded to research laboratories. Among these, our laboratory handled a median of 16 unstored samples/month, corresponding to more than 1,500 UCB units processed in the past 15 years. All the samples were analyzed within a timelapse of 0 to 5 days from the date of collection, with most of them $(\sim 80 \%)$ processed within 3 days ( - Fig. 1A). A retrospective analysis of these samples showed a median volume of $75 \mathrm{~mL} /$ unit and a median cell count of $10 \times 10^{3} / \mu \mathrm{L}$ white blood cells, $3 \times 10^{6} / \mu \mathrm{L}$ red blood cells, and $200 \times 10^{3} / \mu \mathrm{L}$ platelets (-Fig. 1B-E). The percentage of $\mathrm{CD} 34^{+}$cells was approximately $0.2 \%$ (-Fig. 1B). Of these, we separated a median of $0.85 \times 10^{6} \quad \mathrm{CD}^{+} \quad$ cells/UCB (range:

(c) 2020. Thieme. All rights reserved. Georg Thieme Verlag KG,

Rüdigerstraße 14,

70469 Stuttgart, Germany
DOI https://doi.org/ 10.1055/s-0040-1719028. ISSN 0340-6245. 
A

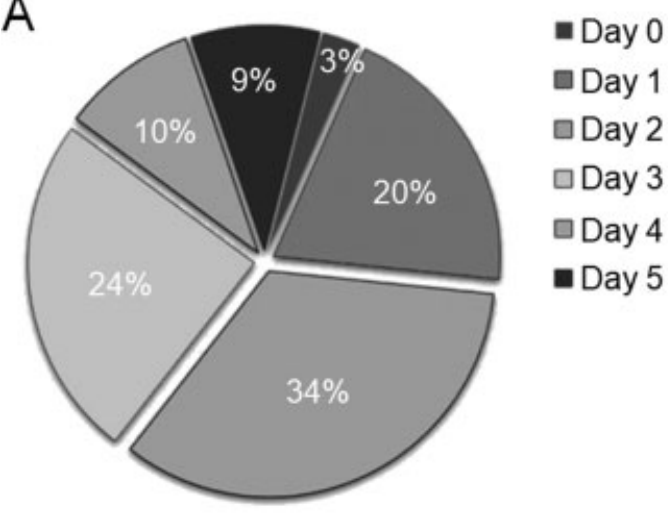

\begin{tabular}{|c|c|c|c|}
\hline \multirow{2}{*}{ B } & Median & Min & Max \\
\hline $\begin{array}{c}\text { Volume } \\
(\mathrm{mL})\end{array}$ & 75.5 & 46 & 123 \\
\hline $\begin{array}{c}\text { WBC } \\
\left(10^{3} / \mu \mathrm{L}\right)\end{array}$ & 9.9 & 3.3 & 23.5 \\
\hline $\begin{array}{c}\mathrm{RBC} \\
\left(10^{6} / \mu \mathrm{L}\right)\end{array}$ & 3.07 & 1.6 & 6.3 \\
\hline $\begin{array}{c}\mathrm{PLT} \\
\left(10^{3} / \mu \mathrm{L}\right)\end{array}$ & 201 & 20 & 351 \\
\hline $\begin{array}{c}\mathrm{CD} 34^{+} \mathrm{cells} \\
(\%)\end{array}$ & 0.17 & 0.0074 & 0.3 \\
\hline
\end{tabular}

\section{F}

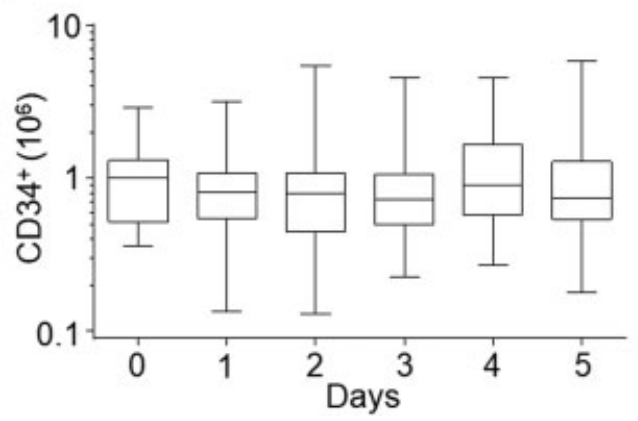

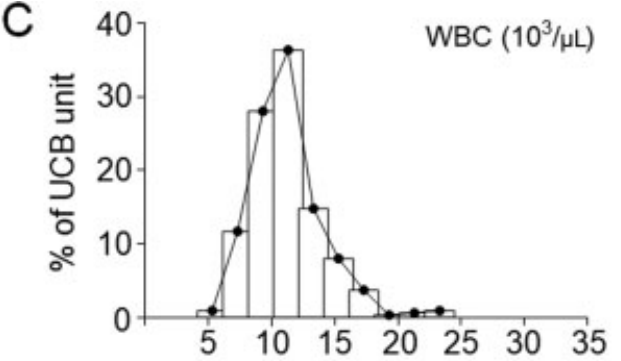
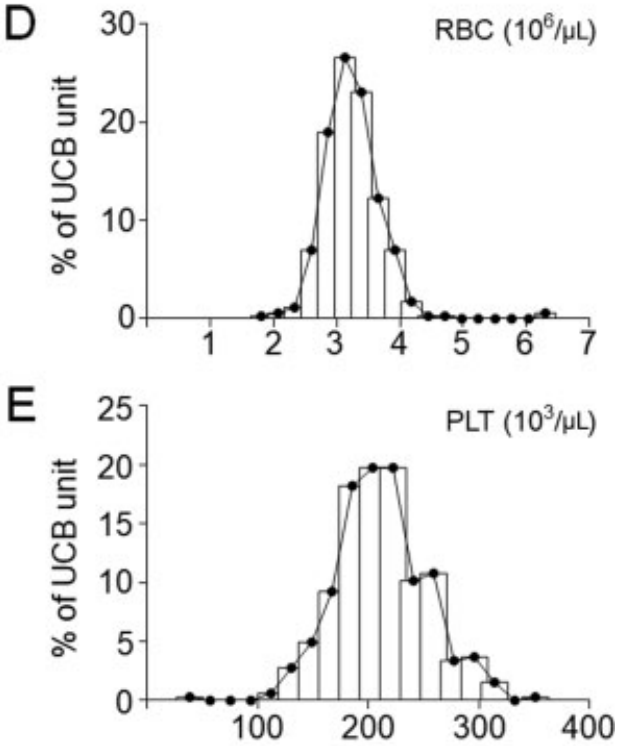

G

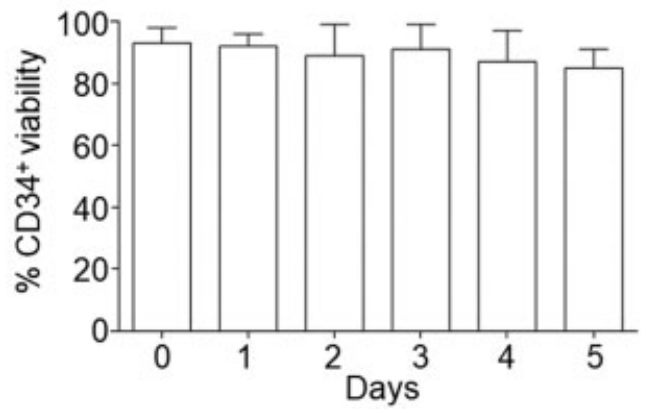

Fig. 1 General characteristics of umbilical cord blood units. (A) Percentage of samples processed in the different day intervals. (B) Median values and range of the volume and total cell count of umbilical cord blood (UCB) units (WBC, with blood cell; RBC, red blood cell; PLT, platelet). Based on the concentration of (C) WBCs, (D) RBCs, and (E) PLTs, UCB unit distribute with a Gaussian-like distribution within the range of analysis. (F) Box and whisker diagram of the number of $\mathrm{CD} 34^{+}$cells obtain from the UCB samples according to the day interval in which the sample was processed $(p=N S)$. (G) Percentage of viable CD34 ${ }^{+}$cells obtained from the UCB samples according to the day interval in which the sample was processed. Data are expressed as mean and standard deviation (SD) $(p=N S)$.

0.13-5.8 $\times 10^{6}$ ), by immunomagnetic sorting procedure. No significant differences were observed in the number and viability of $\mathrm{CD} 34^{+}$cells isolated from day 0 to 5 (- Fig. 1F, G), thus supporting the notion that UCB CD $34^{+}$cell survival can last for several days after collection. ${ }^{1}$

Upon harvesting, $1 \times 10^{6} \mathrm{CD} 34^{+}$cells $/ \mathrm{mL}$ were cultured in a serum-free medium in the presence of $10 \mathrm{ng} / \mathrm{mL}$ TPO and $10 \mathrm{ng} / \mathrm{mL}$ interleukin (IL)-11, which were renewed every 3 days over 2 weeks of differentiation. The median number of viable Mks quantified at the end of each culture was $1 \times 10^{6}$ (range: $0.1-7 \times 10^{6}$ ). A significant correlation between the input number of $\mathrm{CD} 34^{+}$cells and the corresponding number of differentiated $C D 41^{+} \mathrm{CD} 42 \mathrm{~b}^{+}$Mks was shown by linear regression analysis $\left(R^{2}=0.85, p<0.0001\right.$; - Fig. $\left.2 \mathrm{~A}\right)$, regardless of the timing of UCB processing after collection, thus demonstrating that UCB CD34 ${ }^{+}$cells maintain full differentiation capability over 5 days after sampling. These data highlight the efficient rate of success of our culture conditions that support the differentiation of one mature Mk per starting $\mathrm{CD}^{+} 4^{+}$cell, rather than the proliferation of immature progenitors. Comparable results were obtained after thawing cryopreserved $\mathrm{CD}_{3} 4^{+}$cells, consistent with previous knowledge about the efficient recovery of UCB HSCs after several years of storage. $^{17}$ 
A

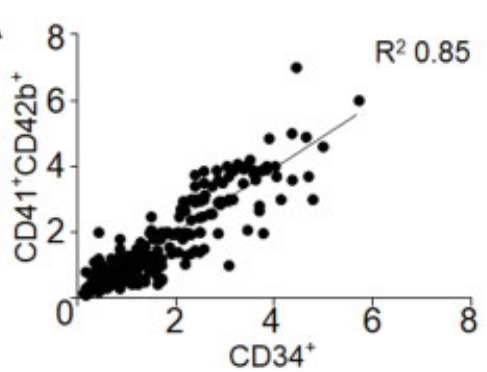

D

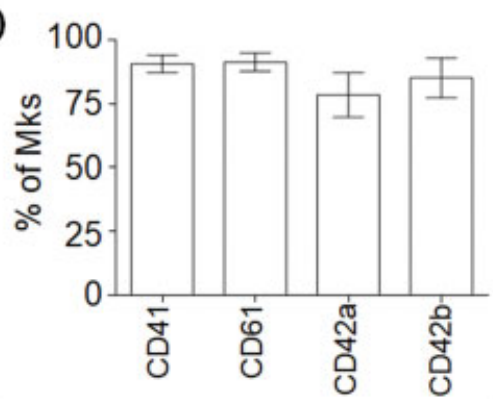

B

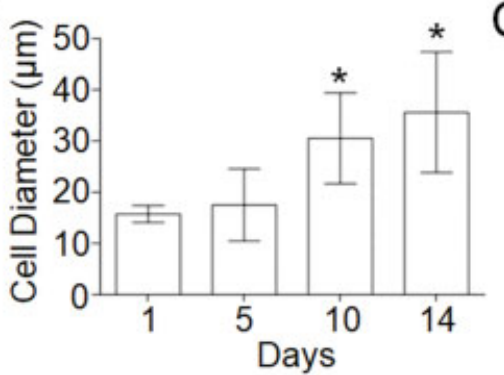

E

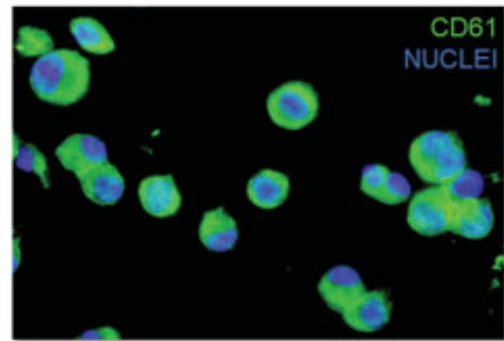

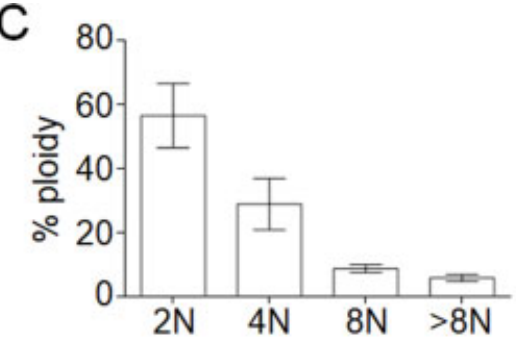

F

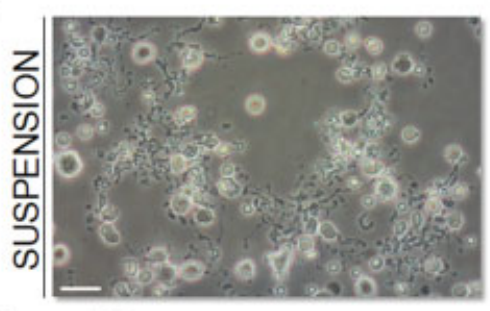

G

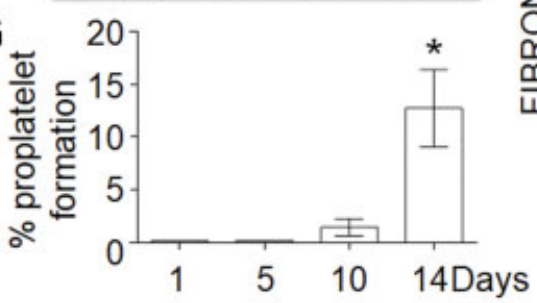

$\mathrm{H}$
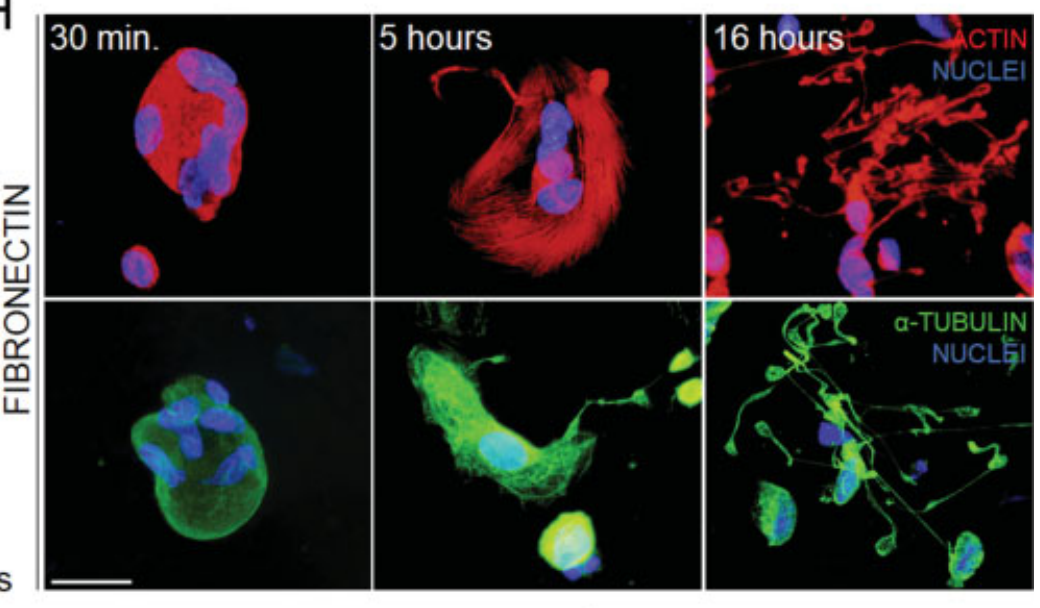

I
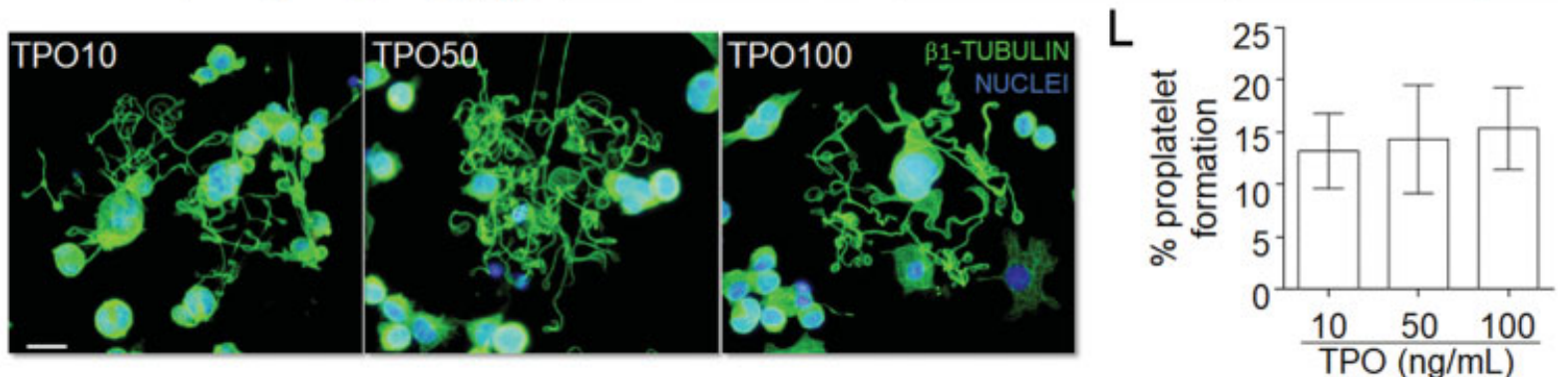

Fig. 2 Megakaryopoiesis from umbilical cord blood hematopoietic stem cells. (A) CD34 ${ }^{+}$cells were cultured in a serum-free medium in the presence of interleukin (IL)-11 $(10 \mathrm{ng} / \mathrm{mL})$ and thrombopoietin (TPO) $(10 \mathrm{ng} / \mathrm{mL})$ for 2 weeks. Linear regression analysis of the number of CD34 ${ }^{+}$cells at the input and $\mathrm{CD} 41^{+} \mathrm{CD} 42 \mathrm{~b}^{+}$at the output proved to be significant with an $R^{2}=0.85$. (B) The diameter of cells was measured randomly throughout the culture, to assess the rate of maturation. Data are expressed as mean \pm standard deviation (SD) $(p<0.05)$. (C) Megakaryocyte (Mk) ploidy was quantified at the end of the culture by flow cytometry by gating $\mathrm{CD} 41^{+}$events within the corresponding parameters of size and complexity to mature Mks. Data are expressed as mean \pm SD. (D) Panning of cell surface maturity markers on Mks on the 14th day of culture was performed by flow cytometry. Data are expressed as mean \pm SD. (E) Differentiation was confirmed by fluorescence microscopy (green: CD61; red: CD41; blue: nuclear stain Hoechst 33258; scale bar: $30 \mu \mathrm{m}$ ). (F) Representative light microscopy images of proplatelet formation by Mks in liquid culture (scale bar $=50 \mu \mathrm{m}$ ). (G) The percentage of proplatelet forming Mks was calculated as the number of cells displaying long filamentous pseudopods with respect to the total number of round Mks per analyzed field. Histograms show the percentage of proplatelet formation throughout the culture. Data are expressed as mean $\pm \operatorname{SD}\left({ }^{*} p<0.01\right)$. (H) Mks at day 13 of culture were plated on fibronectin-coated coverslips. After 30 minutes, 5 hours, or 16 hours of incubation adherent cells were fixed and stained for immunofluorescence analysis with TRITC-phalloidin (red) and antibody against $\alpha$-tubulin (green). Nuclei were counterstained with Hoechst 33258 (blue). Scale bar $=30 \mu \mathrm{m}$. (I) CD34 $4^{+}$cells were cultured in a serum-free medium in the presence of IL-11 $(10 \mathrm{ng} / \mathrm{mL})$ and increasing concentrations of TPO $(10-50-100 \mathrm{ng} / \mathrm{mL})$. Analysis of proplatelet structure was performed after 2 weeks by immunofluorescence staining of the Mk-specific cytoskeleton component $\beta 1$-tubulin (green = $\beta 1$-tubulin; blue $=$ nuclei; scale bar $=25 \mu \mathrm{m}$ ). In all tested conditions, the representative pictures show similar elongation of proplatelet shafts with the presence of bulbous tips, at the terminal ends of each branch, resembling mature platelets. (L) The analysis of the percentage of proplatelet forming Mks in the different tested conditions show comparable Mk function. Data are expressed as mean $\pm \mathrm{SD}(p=\mathrm{NS})$. 
During differentiation, a progressive increase in the percentage of cells with high diameter, ploidy, and expression of lineage-specific markers was observed (-Fig. 2B-E). Electron microscopy analysis demonstrated the development of the demarcation membrane system and the presence of granules throughout the cytoplasm ( $\sim$ Supplementary Fig. S1, available in the online version). At the end of the culture $>95 \%$ of Mks were viable ( - Supplementary Fig. S2, available in the online version) and approximately $91 \pm 5 \%$ of cells expressed late-stage differentiation markers, such as CD41 and CD42b. Of these, approximately $13 \pm 3 \%$ Mks elongated branched proplatelets in liquid culture ( $\mathbf{- F i g . ~ 2 F}$, G). The process of proplatelet formation was spontaneously initiated by Mks and burst between day 13 and 14 of differentiation, independently of the presence of any cytokines, including TPO. This was probably due to the regulation of proplatelet formation through autocrine-paracrine signaling, ${ }^{18,19}$ even though the exact mechanisms that drive proplatelet formation are still unknown. ${ }^{20}$ Platelet-like particles could be found in the culture medium (-Supplementary Fig. S1, available in the online version). Additionally, in our three-dimensional silk-based bone marrow models we demonstrated that UCB-derived Mks release platelets with the same morphological and functional features of peripheral blood platelets. ${ }^{21-23}$

In vivo Mk function is supported by the interaction with extracellular matrix components. Among these, fibronectin is known to support proplatelet formation. ${ }^{13,24}$ Upon adhesion on fibronectin, we showed that Mks activate different cellular processes: (1) early passive adhesion; (2) stress fiber formation and microtubule polymerization with proplateletlike pseudopod formation; and (3) proplatelet branching (- Fig. 2H). Mk cultures with increasing concentrations of TPO, from 10 to $100 \mathrm{ng} / \mathrm{mL}$, did not prompt further $\mathrm{Mk}$ differentiation or proplatelet formation (-Fig. 2I, L).

In summary, we developed a protocol to differentiate Mks from UCB CD34 ${ }^{+}$cells using minimal concentrations of TPO and IL-11. The analysis of 1,500 UCB samples indicates that our culture protocol is highly reproducible and represents a gold standard for the study of human megakaryopoiesis. UCB HSCs are cells of fetal/neonatal origin, and Mks derived from these cells present distinct characteristics such as high proliferation rate, low ploidy, and mature cytoplasm. For this reason, low-ploidy neonatal Mks are more mature than adult low-ploidy Mks. ${ }^{14}$ Despite these differences, our protocol has been designed to promote exclusively Mk maturation resulting in almost one $\mathrm{CD} 41^{+} \mathrm{CD} 42 \mathrm{~b}^{+}$Mk per $\mathrm{CD} 34^{+}$ cell. The controlled proliferation in our cultures leads to the production of a uniform population of $\mathrm{CD} 41^{+} \mathrm{CD} 42 \mathrm{~b}^{+}$Mks. The consistency of this protocol makes these Mks a highly reliable tool for different studies ranging from basic science to disease modeling and drug testing. ${ }^{12,13,25}$

\section{Authors' Contributions}

C.A.D.B. designed research studies, conducted experiments, acquired data, analyzed data, and wrote the manuscript. P.M.S. conducted experiments, acquired data, analyzed data, and wrote the manuscript. C.P.M. analyzed data and wrote the manuscript. C.P. and C.D.F. provided cord blood samples, analyzed data, and edited the manuscript. A.B. designed and supervised the research project, acquired data, analyzed data and wrote the manuscript.

\section{Funding}

This paper was supported by Cariplo Foundation (2013-0717 and 2017-0920) and 'Progetti Di Ricerca Di Rilevante Interesse Nazionale' (PRIN 2017Z5LR5Z). The funders had no role in study design, data collection and analysis, decision to publish, or preparation of the manuscript.

\section{Conflict of Interest}

None declared.

\section{Acknowledgments}

The authors would like to thank all the families for their invaluable support to research when choosing to donate cord blood. We thank "Centro Grandi Strumenti" of the University of Pavia for technical assistance with transmission electron microscopy.

\section{References}

1 Broxmeyer HE, Douglas GW, Hangoc G, et al. Human umbilical cord blood as a potential source of transplantable hematopoietic stem/progenitor cells. Proc Natl Acad Sci U S A 1989;86(10): 3828-3832

2 Mayani H, Wagner JE, Broxmeyer HE. Cord blood research, banking, and transplantation: achievements, challenges, and perspectives. Bone Marrow Transplant 2020;55(01):48-61

3 de Wynter EA, Buck D, Hart C, et al. CD34+AC133+ cells isolated from cord blood are highly enriched in long-term culture-initiating cells, NOD/SCID-repopulating cells and dendritic cell progenitors. Stem Cells 1998;16(06):387-396

4 Lu L, Xiao M, Shen RN, Grigsby S, Broxmeyer HE. Enrichment, characterization, and responsiveness of single primitive CD34 human umbilical cord blood hematopoietic progenitors with high proliferative and replating potential. Blood 1993;81(01): 41-48

5 Capone F, Lombardini L, Pupella S, Grazzini G, Costa AN, Migliaccio G. Cord blood stem cell banking: a snapshot of the Italian situation. Transfusion 2011;51(09):1985-1994

6 Roura S, Pujal JM, Gálvez-Montón C, Bayes-Genis A. The role and potential of umbilical cord blood in an era of new therapies: a review. Stem Cell Res Ther 2015;6:123

7 Rai J, Kaushik K. Reduction of animal sacrifice in biomedical science \& research through alternative design of animal experiments. Saudi Pharm J 2018;26(06):896-902

8 Ito Y, Nakamura S, Sugimoto N, et al. Turbulence activates platelet biogenesis to enable clinical scale ex vivo production. Cell 2018; 174(03):636-648

9 Takayama N, Eto K. In vitro generation of megakaryocytes and platelets from human embryonic stem cells and induced pluripotent stem cells. Methods Mol Biol 2012;788:205-217

10 Huang CY, Liu CL, Ting CY, et al. Human iPSC banking: barriers and opportunities. J Biomed Sci 2019;26(01):87

11 Tomer A. Human marrow megakaryocyte differentiation: multiparameter correlative analysis identifies von Willebrand factor as a sensitive and distinctive marker for early ( $2 \mathrm{~N}$ and $4 \mathrm{~N}$ ) megakaryocytes. Blood 2004;104(09):2722-2727

12 Di Buduo CA, Abbonante V, Marty C, et al. Defective interaction of mutant calreticulin and SOCE in megakaryocytes from patients 
with myeloproliferative neoplasms. Blood 2020;135(02): 133-144

13 Balduini A, Pallotta I, Malara A, et al. Adhesive receptors, extracellular proteins and myosin IIA orchestrate proplatelet formation by human megakaryocytes. J Thromb Haemost 2008;6(11): 1900-1907

14 Liu ZJ, Italiano J Jr, Ferrer-Marin F, et al. Developmental differences in megakaryocytopoiesis are associated with up-regulated TPO signaling through mTOR and elevated GATA-1 levels in neonatal megakaryocytes. Blood 2011;117(15):4106-4117

15 D'Atri LP, Rodríguez CS, Miguel CP, et al. Activation of toll-like receptors 2 and 4 on $\mathrm{CD}_{4} 4^{+}$cells increases human megakaryo/thrombopoiesis induced by thrombopoietin. J Thromb Haemost 2019;17(12):2196-2210

16 Bhatlekar S, Basak I, Edelstein LC, et al. Anti-apoptotic BCL2L2 increases megakaryocyte proplatelet formation in cultures of human cord blood. Haematologica 2019;104(10):2075-2083

17 Broxmeyer HE, Cooper S. High-efficiency recovery of immature haematopoietic progenitor cells with extensive proliferative capacity from human cord blood cryopreserved for 10 years. Clin Exp Immunol 1997;107(Suppl 1):45-53

18 Balduini A, Di Buduo CA, Malara A, et al. Constitutively released adenosine diphosphate regulates proplatelet formation by human megakaryocytes. Haematologica 2012;97(11):1657-1665
19 Nagata Y, Yoshikawa J, Hashimoto A, Yamamoto M, Payne AH, Todokoro K. Proplatelet formation of megakaryocytes is triggered by autocrine-synthesized estradiol. Genes Dev 2003;17(23): 2864-2869

20 Ghalloussi D, Dhenge A, Bergmeier W. New insights into cytoskeletal remodeling during platelet production. J Thromb Haemost 2019;17(09):1430-1439

21 Di Buduo CA, Wray LS, Tozzi L, et al. Programmable 3D silk bone marrow niche for platelet generation ex vivo and modeling of megakaryopoiesis pathologies. Blood 2015;125(14): 2254-2264

22 Di Buduo CA, Soprano PM, Tozzi L, et al. Modular flow chamber for engineering bone marrow architecture and function. Biomaterials 2017; 146:60-71

23 Tozzi L, Laurent PA, Di Buduo CA, et al. Multi-channel silk sponge mimicking bone marrow vascular niche for platelet production. Biomaterials 2018;178:122-133

24 Di Buduo CA, Moccia F, Battiston M, et al. The importance of calcium in the regulation of megakaryocyte function. Haematologica 2014;99(04):769-778

25 Di Buduo CA, Currao M, Pecci A, Kaplan DL, Balduini CL, Balduini A. Revealing eltrombopag's promotion of human megakaryopoiesis through AKT/ERK-dependent pathway activation. Haematologica 2016;101(12):1479-1488 